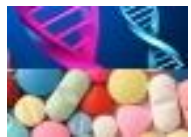

www.ejosat.com ISSN:2148-
European Journal of Science and Technology

Special Issue, pp. 411-417, October 2019

Copyright (C) 2019 EJOSAT

Research Article

\title{
Karabük İlindeki Alçak Gerilim Dağıtım Sistemlerinde Elektrik Tüketiminin Analizi
}

\author{
Mehmet Fahri Yapıcıoğlu ${ }^{1 *}$, Hasan Hüseyin Sayan ${ }^{2}$, Hakan Terzioğlu ${ }^{13}$ \\ ${ }^{I}$ Enerjisa Başkent Electricity Distribution Inc. , Çankir/Turkey, mehmetfahri.yapicioglu@eedas.com (ORCID: 0000-0003-4389-4000) \\ ${ }^{2}$ Gazi University, Ankara/Turkey, hsayan@gazi.edu.tr (ORCID: 0000-0002-0692-172X) \\ ${ }^{3}$ Konya Technical University, Konya/Turkey, hterzioglu@ktun.edu.tr (ORCID: 0000-0001-5928-8457)
}

(First received 1 August 2019 and in final form 25 October 2019)

(DOI: $10.31590 /$ ejosat.638375)

ATIF/REFERENCE: Yapıcığlu, M. F., Sayan, H. H. \& Terzioğlu, H. (2019). Karabük İlindeki Alçak Gerilim Dağıtım Sistemlerinde Elektrik Tüketiminin Analizi. European Journal of Science and Technology, (Özel Say1), 411-417.

\begin{abstract}
Özet
Elektrik İç Tesisat Projeleri; yapıların elektrik tesis ihtiyaçlarının belirtildiği en temel platformdur. Bu projelerde tüm tasarım ve hesaplamalar; Elektrik İç Tesisler Yönetmeliği, Elektrik Tesisleri Proje Hazırlama Yönetmeliği, Kablo Bacasi Ve Enerji Odasının Ölçü Ve Detayları İle Uygulama Alanlarına İlişkin Esaslar ve ilgili lokal genelgeler referans alınarak yapılır. Hazırlanan projeler sorumlu Elektrik Dağıtım Şirketlerince yine yukarıda belirtilen mevzuat hükümleri referans alınarak kontrol edilir ve onaylanırlar. Elektrik İç Tesisat Projelerinde; tesisin güvenliğini, maliyetini ve verimliliğini etkileyen en önemli hesaplamalardan biri "talep gücü" hesabıdır. “Talep gücü” projede belirtilen tüm elektriksel güçlerin toplamı (kurulu güç) ile güçlerin niteliklerine (aydınlatma yükü, priz yükü, mekanik yük vs.) göre uygun "eş zamanlılık katsayılarla” çarpılması ile elde edilmektedir. Tesislerin ölçü, iletim ve koruma elemanları talep gücü referans alınarak seçilmektedir. Dolayısı ile yapılara ait elektriksel malzemelerin ideal değerlerde belirlenebilmesi için Elektrik İç Tesisat Projelerinde “eş zamanlılık katsayısı” büyük rol oynamaktadır. Mevcut durumda Elektrik İç Tesisat Projelerinde talep gücü hesaplamaları; yıllar önce hazırlanan ve günümüz şartlarındaki gelişimlere ve sürekli yenilenen teknolojiye cevap veremeyen Elektrik İç Tesisler Yönetmeliği' nin 57.MADDE sinin a.2 bendi'nde belirtilen eş zamanlılık katsayıları referans alınarak yapılmaktadır. Talep gücü hesabının gelişen yaşam standartları ve güncel teknolojiye paralel olarak ideal şartlarda yapılması tüm yapıların elektrik tesislerinin performans ve maliyet bakımından güvenirliliğini artıracaktır. Bu makalede eşzamanlılık katsayısının güncel ihtiyaçları karşılamadığını, gerçek değerlerle hesaplanan değerler arasında büyük farklar olduğunu ve bu farklılığın maliyet etkisinin neler olduğunu Karabük İli için 1814 yapı, 5591 müşterinin, 4 yıllık gerçek tüketim değerlerini analiz edeceğiz. Böylece eşzamanlılık katsayısının önemi vurgulanmış olacaktır.
\end{abstract}

Keywords: Kurulu güç, eş zamanlı güç, eş zamanlılık katsayısı, Elektrik İç Tesisat Projesi.

\section{Analysis of Electricity Consumption in Low Voltage Distribution Systems in Karabük}

\begin{abstract}
Electrical Interior Installation Projects; It is the most basic platform where the electrical installation needs of the buildings are specified. All projects and calculations in these projects; Electrical Interior Facilities Regulation, Electrical Facilities Project Preparation Regulation, Cable Chimney and Energy Chamber Measures and Details of the Application Areas and relevant local circulars are made with reference. The prepared projects are controlled and approved by the responsible Electricity Distribution Companies again with reference to the provisions of the legislation mentioned above. In Electrical Interior Installation Projects; One of the most important calculations affecting the security, cost and efficiency of the facility is the "demand power" account. "Demand power toplam is obtained by multiplying the sum of all the electrical powers specified in the project (installed power) with
\end{abstract}


appropriate" concurrency coefficients göre according to the characteristics of the powers (lighting load, socket load, mechanical load, etc.). The measurement, transmission and protection elements of the plants are selected with reference to the demand power. Consequently, "concurrency coefficient" plays an important role in the Electrical Interior Installation Projects in order to determine the electrical materials of the buildings at ideal values. Currently, demand power calculations in Electrical Interior Installation Projects; It is based on the concurrency coefficients mentioned in Article a.2 of Article 57 of the Electricity Indoor Facilities Regulation which is prepared many years ago and cannot respond to the developments in today's conditions and continuously renewed technology. Performing the demand power calculation under ideal conditions in parallel with the developing living standards and current technology will increase the reliability of the performance and cost of the electrical installations of all buildings. In this article, we will analyze the real consumption values of 1814 buildings, 5591 customers and 4 years for Karabük Province, that the concurrency coefficient does not meet current needs, that there are large differences between real values and calculated values and what is the cost effect of this difference. Thus, the importance of the concurrency coefficient will be emphasized.

Keywords: Kurulu güç, eş zamanlı güç, eş zamanlılık katsayısı, Elektrik İç Tesisat Projesi.

\section{Giriş}

Gelişen teknolojiler, değişen yaşam şartları ve günümüz insanlarının beklentileri yapılacak tüm plan ve projelerde beklentileri artırmaktadır. Enerjinin kısıtlı ve pahalı olduğu dünyamızda "enerji verimliliğinin” gözardı edilmesi de mümkün değildir. Beklentileri ve enerji verimliliğini odak kabul ederek hazırlanacak plan ve projeler ancak performansı yüksek projeler olacaktır. Kurulu güce ait veriler elektrik iç tesisat projelerinde belirlenmelidir. [1] Özellikle maliyeti ve riski yüksek olan inşaat, mekanik ve elektrik gibi projelerde önceden yapılan simülasyonlar, tasarımlar ve hesaplamalar hem verimlilik hemde riskleri azaltmak için ciddi önem arz etmektedirler.[2][3][4][5] Birçok projede tasarım esnasında dikkate alınan hassasiyetler performansa ve verimliliğe katkı sağladığı gibi Elektrik İç Tesisat Projelerinde de yapılan "eş zamanlı güç" hesaplamaları, yapıların elektriksel tesis kalitesine, performansına ve verimliliğine katkı sağlamaktadır. Elektrik tesislerinde malzeme seçimi ve tasarımı; Elektrik İç Tesisat Projelerinde hesaplanan "talep gücü/eşzamanlı güç” referans alınarak yapılır. Eş zamanlı güç, (aynı zamanda çekilen güç) kurulu güç ile eş zamanlılık katsayısının çarpılmasından elde edilir.

Şebekelerin güç değerlerinin incelenmesi ile ilgili çeşitli çalışmalar gerçekleştirilmiştir. (Sun et al., 2010) tarafından Guiyang şehir elektrik şebekesinden gerçek hayattaki verilerle yapılan çalışmada, yüksek enerjili tüketicinin güç talebi modelini oluşturmak için veri madenciliği temelli bir yöntem önerilmiştir. Gerçekleştirilen model de, yüksek enerjili tüketicinin güç talebi ile piyasa faktörleri arasındaki bir tür nicel ilişkiyi tanımlamaktadır. Böyle bir model, talep tahminleri ve talep tarafı yönetimine DSM için, özellikle de büyük oranda yüksek enerji tüketen tüketicilere sahip elektrik şebekeleri için faydalı olabileceği görülmüştür. Ancak, yüksek enerjili tüketici için tarihsel verilerin olmaması talep modellemesinde ilk baştaki sorun olmakla beraber, daha başka sorunlarda bulunduğu ifade edilmiştir. (Zheng et al., 2018)tarafından Tianjin'in ekonomik brütünü tahmin etmek için ARMIR modelini kullanmaktadır ve ekonomik tahmine dayalı vektör otoregresif modelini kullanarak güç talebini öngörülmektedir. Ekonomi ve enerji talebi arasındaki ilişkiye odaklanmakta, enerji talebi tahmininin sonucunu ortaya koymakta ve enerji şebekesi planlamasının temelini atmaktadır.Yapılan araştırma ile şu sonuçlar çıkartılmıştır; 1) Şu anda, Tianjin sanayileşme aşamasının ikinci yarısında, elektriğin talep artışı daralma döneminden genişleme dönemine doğru değişmekte ve büyüme hızı yavaşlamaktadır. 2) Tianjin'de ekonomik büyüme ile güç talebi arasında tek yönlü bir Granger nedensellik var ve güç talebindeki artış, ikinci üretim, üçüncü üretim artışı ve tüketim artışı ile daha yüksek korelasyon katsayısına sahiptir. 3) Tianjin'in ekonomik döngüsü yaklaşık 15, güç döngüsü yaklaşık 17, ekonomik döngünün zirvesi elektrik döngüsünden iki yıl sonra ve güç "Onüç-Beş" döneminde genişleme döneminde. Tianjin elektrik şebekesinin talep seviyesi 2020'de 104,8 Milyar kilowatt'a ulaştığında, "Onüç Beş" yıllık ortalama büyüme\% 6.68'dir. (Hong-Tao, Jian-Xue, Yang, Meng, \& Ge, 2018) tarafından öncelikle rüzgar ve fotovoltaik enerji yerel tüketim modelinin yolları ve talep tarafi cevabına dayanan talep tarafı yanıt maliyet fonksiyonu incelenmiştir. Bu makale Gansu eyaletini farklı mevsimlerde en uygun çözümü bulmak için örnek almaktadır. Bu yazıda, talep tarafı yanıtı perspektifinden yerel rüzgar ve fotovoltaik güç tüketiminin nasıl destekleneceği tartışılmaktadır ve talep tarafı yanıtına dayalı bir yerel tüketim modeli oluşturulmaktadır. Sonuçlar, rüzgar enerjisi ve fotovoltaik tüketiminin önemli ekonomik faydalar ve çevresel faydalar getireceğini göstermektedir, ancak farklı senaryolarda talep tarafı tepkisinin etkinliği ve derecesi farklı olmaktadır. (Khare, Bajpai, \& Choubey, 2012) tarafından Bu çalışma, yoğun yükleme dönemlerinde talebi optimize etmek için yükü faydadan DG ayarına kaydırma tekniklerinden birini göstermektedir. Bu yazıda, bağlantı şeması detaylarıyla ve hat diyagramı yardımıyla ana besleme yüklerinin detayları ile birlikte JNKVV FEEDER-II (Kayıt İşleri Ofisi Besleyicisi) anlatılmaktadır. Elektrik faturasındaki MD ücretlerinin aşılması, Tescil Ettiren Besleyici Biriminde azaltıldı, tasarruf yaklaşık 6,08 Rs / dak. Enerji tüketiminde kamu hizmeti sayesinde genel tasarruf yılda 36000 adede kadar çıkarıldı. (Bin et al., 2018) tarafından $\mathrm{Bu}$ çalışma Çin'in ulusal koşullarıyla birleştirildiğinde, talep yanıtına dayanarak esnek bir yük kontrolü geliştirmek için bir öneri sunmaktadır. Bu makale esnek yük düzenleme teknolojisini düzenleme ve işletme açısından incelemektedir. Esnek yük kontrolü açısından yandaki fikirler önerilmiştir. 1) Enerji şirketleri ve enerji kullanıcılarının rehberliklerini güvenlik, ekonomi, enerji tasarrufu ve emisyonların azaltılması yönünden güçlendirin ve esnek yüklerin enerji şebekelerinin düzenlenmesi ve işletilmesinde ve ayrıca enerji üretim birimlerinin yeterli avantajlar sunulmasını sağlayın. 2) Yerel enerji üretimi kaynak donanımlarına ve esnek yük bileşenlerine göre, makul bir iz kontrol modu oluşturunuz. 3) Jeneratör setinin kapasitesinin yetersiz olduğu bölgesel elektrik şebekesinde, elektrik şebekesini düzenleme için teşvik ve telafi mekanizmasına katılmak için esnek yükü mümkün olan en kısa sürede iyileştiriniz ve esnek bir yük kontrolü gösteri projesi oluşturunuz. (Westermann \& John, 2007) tarafından $\mathrm{Bu}$ makale, daha etkili ağ kullanımı için geniş alan izleme ve kontrol sistemlerinin talep tarafı yönetim uygulamaları ile birleştirilmesinin faydalarını özetlemektedir.II. Bölüm, ses frekansı dalgalanma kontrolüne dayanan bir temel DSM teknolojisini özetlemektedir.Genel işlevsel mimari taslak, Bölüm III'te açıklanmaktadır Bölüm IV'teki vaka incelemesi bu senaryoyu özetliyor ve 
optimum iletim koridor yükleri ve minimum spot piyasa enerji satın alımı için talep tarafı yönetimin (DSM) geniş alan kontrol sisteminin yararını çizmektedir. Özet olarak, dalgalanma kontrol teknolojisine dayanan geniş alanlı bir kontrol sisteminin uygulanması, güç sisteminin çalışması bağlamında birçok ekonomik avantaj sağlamaktadır. (Quan, Baoguo, Xiandong, Yuanbing, \& Zhaoguang, 2009) tarafından Güç kaynağı ve talep konusundaki öngörünün karmaşıklığı ve belirsizliği bu yazıda incelenmiştir ve nitel analizden nicel analize kadar insan bilgisayar entegrasyonunun meta sentez yöntemini çalışmaktadır. Bu yazıda, II. Bölümde atölye için meta-sentez ve salonun temel teorisi tanıtılacak, elektrik enerjisi talebinin meta-sentezi atölye salonunun yapısı ve arz araştırması, III. Bölümde ele alınacaktır. Bölüm IV'te gösterilecek, sonuçta Bölüm V' de sonuç verilecektir. Uzmanlar 2009'un Çin makro ekonomisini incelemişlerdir, birçok makroekonomik gösterge analiz edilmiş ve tahmin edilmiştir. Tahmin edilen GSYH büyüme oranı\% 8 olacak ve elektrik tüketimi\% 4.7 artacaktır. Güç kaynağ1 ve talebi ile ilgili HWSME (Power HWSME) teorik temeli, makroekonomik ve güç arz ve talebini incelemek için etkili bir teori olduğunu doğrulayan meta-sentezdir. (Jiarui et al., 2018) tarafından bu yazıda, kullanıcı elektrik yükleri ve dağıtılmış üretim dikkate alınarak, elektrik piyasasının müdahale stratejisi, en yüksek vadi kullanım süresi tarifesine ve Kontrollü yük sevkiyata göre ele alınmıştır. Bu planın yeni enerji dağıtımının verimliliğini artırabileceği ve gelecekte akıllı elektrik kullanım stratejisi için teorik bir temel sağladığı kanıtlanmıştır. Elektrik üretimine ve elektrik tüketimine göre makul ölçüde, Elektrik şebekesinin yük eğrisini iyileştirmek için, Tepe kaymasını ve vadi doldurmayı gerçekleştirmektedir. Bu yazıda, konut sakinleri için elektrik yükünün sınıflandırılması ve modellenmesi, akıllı güç tüketiminin teknik altyapısını akıllı şebeke altında birleştirmekte ve DG'nin özellikleri analiz edilmektedir. (Zhao-guang \& Xian-dong, 2006) tarafından Bu makale simülasyon sisteminin mimarisini üç açıdan incelemeyi amaçlamaktadır: yazılım yapısı, veritabanı platformu ve sistem fonksiyonel modülünü incelemeyi amaçlamıştır. Bu makalede, çalışma üç açıdan incelenmektedir: yazılım yapısı, veritabanı platformu ve sistem fonksiyonel modülü. Bu mimariye dayanan simülasyon sistemi dört hedefe ulaşmıştır:(1) özellikleri yoğunlaştırılmış veri, geniş kapsam ve tam içerikli, güç kaynağı ve talep veritabanı platformu oluşturmak, kapsamlı ve eksiksiz içerik sağlamak, veri sorgusu ve veri analizi yapmak; (2) tüm ülke ekonomisinin, sanayi politikalarının ve ilgili endüstrilerin yanı sıra tüm ülkede elektrik arz ve talebinin, tüm büyük enerji şebekesi ve il elektrik şebekesinin izlenmesi ve analizini yapmak; (3) ülkedeki güç arz ve talebinin dinamik durumunu izlemek ve güç arz ve talebindeki dengesizliği önlemek; (4) akıllı bir politika simülasyonu oluşturmak platfon=karar vericilere referans vermek için ilgili politikaların ve heykellerin etkilerini araştırmak. (Rewatkar, Kewte, Rewatkar, \& Pote, 2017) tarafından Bu makalede, aylık elektrik faturasını sıkıştırabilmek için maksimum güç talebini denetlemek ve yönetmek anlatılmıştır. Bu araştırma çalışması elektrik faturası hesaplamasında aşırı bir değişiklik yapabilir ve insan gücünü ve zaman tüketimini azaltarak yardımlarını yönetime verebilmektedir. (Xie, Zheng, \& Zhang, 2007) tarafından bu yazıda, eksik bilgi içeren ve deneyime sahip olmayan analize dayanan Gray sistemi tarafından, belirli denklemlere sahip olan ya da olmayan değişkenlere iyi uygulanabilen uzun vadeli güç talebindeki duyarlılık analizine odaklanılmaktadır. Bu çalışmada, orijinal etki faktörleri öncelikle Gri İlişkisel Analiz ile elde edilmiştir. Bu yazıda, yıllık güç talebinin duyarlılık analiz modeli gri teori üzerine kuruludur. Bu çalışma, GSYİH, nüfus vb. Gibi etki faktörlerinin öncelikle gri rasyonel analizle analiz edildiği yıllık talebe yönelik duyarlılık analizinin pratik bir yöntemini sağlamayı amaçlamaktadır. (Imanaka, Baba, Shimabuku, Tobaru, \& Uezu, 2015) tarafından Bu makale, adım yanıtında meydana gelen su pompalarının iki aşamalı güç tüketimini bastırmak için "basit ölü vuruş kontrolü” adı verilen bir kontrol yöntemi önermektedir. Bu makale "basit ölü vuruş kontrolü” olarak adlandırılan bir yöntem önermekte ve gerçek bir su servis sitesi kullanılarak yapılan testlerle iki aşamalı yanıtları bastırmanın etkinliğini doğrulamaktadır. Bu yazıda, adım yanıtında hedef güç ve kolay güç arasındaki farkı bastırmak için "basit ölü vuruş kontrolü” adı verilen basit bir kontrol yöntemi önerilmektedir. (Wang, Chen, \& Jiang, 2016) tarafından bu makalede, büyük ölçekli bir rüzgar enerjisi şebekeye entegre edildiğinde talep tarafının en yüksek düzenlemeye katılmasını kolaylaştırmak için bir maliyet dengeleme mekanizması önerilmiştir. EANS yönteminin ve Shapley yönteminin tahsis sonuçlarını karşılaştırdıktan sonra, Shapley değer yöntemi, katılımcıların yardımcı hizmeti daha etkin bir şekilde sunmalarını sağlamak için daha fazla kısıtlayıcı güce sahip olması için maliyet tazminat mekanizmasını önermek için kullanılır. (Elrayyah, 2015) tarafından Yüklerin, iletişim sistemlerine ihtiyaç duyulmadan arz / talep dengesini korumaya katılmasını sağlamak için bu yazıda bir düşüşe dayalı talep yanıt şeması önerilmiştir, ayrıca bu yazıda, mikrogridlerde etkin enerji yönetimini desteklemek için bir düşüşe dayalı talebe cevap sistemi önerilmiştir. Bu yazıda, sarkma mekanizması, mikrogridlerde ki arz ve talebi dengelemek amacıyla talebe cevap vermek üzere genişletilmiştir.Makalede, talep yanıtı için uygun bir düşüş ilişsisi, uygun arz / talep dengelemesi ve istikrarlı bir mikro ızgara işletimi sağlayacak şekilde formüle edilmiştir.

Elektrik tesislerinin maliyet, güvenlik ve performansını direkt etkilediği için Eşzamanlı gücün dolayısı ile eş zamanlılık katsayısının [7] doğru tespit edilmesi ciddi önem arzetmektedir. Yapılara ait elektriksel malzemelerin ideal değerlerde belirlenebilmesi için Elektrik İç Tesisat Projelerinde "eş zamanlılık katsayısı” büyük rol oynamaktadır. "Eşzamanlı güç" hesabının gelişen yaşam standartları ve güncel teknolojiye paralel olarak, ideal şartlarda yapılması tüm yapıların elektrik tesislerinin performans ve maliyet bakımından güvenirliliğini artıracaktır. Eş zamanlılık katsayısılarının hangi durumlarda ne şekilde kullanılacağına dair bilgilendirme için Elektrik İç Tesisleri Yönetmeliği incelenebilir. Gerçekleştirilen bu çalışmada elektrik tesislerinde kullanılan malzeme ve teçhizatın seçiminde etkili olan eş zamanlılık katsayının önemi örneklerle açıklanmıştır. Ayrıca Karabük ili özelinde mevcut katsayılarla yapılan hesaplamaların gerçek tüketim değerlerinden ne kadar uzakta olduğu da grafiklerle ortaya konmaktadır.

\section{Materyal ve Metod}

\subsection{Talep Gücü Hesabı}

Kurulu güç; Bir tesiste bulunan elektrik enerjisi tüketicilerinin anma (etiket) güçlerinin toplamıdır [7], ihtiyaca göre belirlenir ve bu konuda tasarrufta bulunmak çok olası değildir.

Eşzamanlı güç/Talep edilen maksimum güç: Tüketici tarafından talep edilen gücün maksimum değeridir [7]. 
Eşzamanlılık katsayısı: Belirli bir zaman aralığında tüketicilerin veya elektrikli cihazların bir grubunun eş zamanlı (aynı andaki) maksimum talep gücünün, onların aynı zaman aralığı içerisindeki maksimum bireysel talep güçlerinin toplamına oranıdır (Değeri 1 veya 1'den küçüktür.) [7]

Elektrik İç Tesisat Projelerinde; aydınlatma, priz, asansör, mutfak vs güçler belirlenir. Bu güçler kullanım amacına göre; mesken, ticarethane, okul, hastane, resmi daire, otel vb gibi tasnif edilir. Elektriksel yüklerin çeşidi ve kullanım amaçları göz önünde bulundurularak Elektrik İç Tesisler Yönetmeliğinin aşağıda sunulan ilgili kısmı doğrultusunda uygun “eş zamanlılık katsayıları” tespit edilir.

Elektrik İç Tesisler Yönetmeliği [1] madde 57;

a.2- Değişik ek: RG 30/11/1995- 22479) iletken kesitinin belirlenmesi için yapılan hesaplarda eşzamanlı yük (bağlantı gücü) esas alınmalıdır.

Eşzamanlı yükün (gücü) belirlenmesi:

Eşzamanlı güç (aynı zamanda çekilen güç), kurulu güç değeri eşzamanlılık katsayısı ile çarpılarak bulunur. Konutlarda kurulu güç genel olarak aydınlatma gücü, priz gücü ve biliniyorsa elektrikli ev aletlerinin gücünden oluşur.

Konutlarda bir dairenin eşzamanlı yükünün belirlenmesinde aşağıdaki eşzamanlılık katsayıları esas alınmalıdır.

- Kurulu gücün 8 kW'ye kadar olan bölümü için $\quad \% 60$

- Gücün kalan bölümü için $\quad \% 40$

Binanın eşzamanlı yükünü belirlenmesi için aşağıdaki eşzamanlılık katsayıları esas alınmalıdır.

\begin{tabular}{cc} 
Daire Sayısı & Eș Zamanlı Katsayı \\
\cline { 2 - 2 } $3-5$ & 45 \\
$5-10$ & 43 \\
$11-15$ & 41 \\
$16-20$ & 39 \\
$21-25$ & 36 \\
$26-30$ & 34 \\
$31-35$ & 31 \\
$36-40$ & 29 \\
$41-45$ & 28 \\
$46-50$ & 26 \\
$51-55$ & 25 \\
$56-61$ & 24 \\
62 ve daha fazla & 23
\end{tabular}

Köy kasaba ve imar planı bulunmayan alanlarda yapılan tek evlerde ve yazlıklarda bu esaslara uyulmayabilir.

( Değişik ifade: RG 25/10/1996- 22798)Bütün konutlarda eşzamanlı yük 3 kW'dan az olamaz.

Işyerleri, idare binaları, sosyal binalar, sağlık binaları ve benzeri yerlerde eşzamanlı yükün belirlenmesi için kurulu yük aydınlatma yükü, priz yükü, yedekler hariç mekanik tesisat kış-yaz yükünden büyük olanı, asansör yükü ve mutfak yükünden elde edilir.

Mekanik tesisat kış-yaz yükünden büyük olanının eşzamanlılık katsayısı \%100, mutfak yükü için ise eşzamanlılık katsayısı \%70 alınmalıdır. Aydınlatma, priz ve asansör yükü için aşağıda belirtilen eşzamanlılık katsayıları alınmalıdır. Döndürme momentleri yüksektir.

\subsubsection{Talep Gücü Hesaplama Yöntemi}


Tespit edilen eş zamanlılık katsayıları ilgili oldukları kurulu güçler ile çarpılarak birden fazla eş zamanlı güç belirlenir.

$$
\begin{aligned}
& \text { Eşzamanlı güç=Kurulu güç } x \text { Eş zamanlılık katsayısı } \\
& \text { Eşz zamanlılık katsayısı }=\text { eş zamanlı güç } / \text { kurulu güç } \\
& \mathrm{I}=\mathrm{P} /(\mathrm{V} \times \sqrt{ } 3 \times \operatorname{Cos} \varnothing)=\mathrm{P} /(380 \times 1,73 \times 0,8) \\
& \mathrm{I}=\mathrm{P} / 526
\end{aligned}
$$

\section{Araştırma Sonuçları ve Tartışma}

\subsection{Karabük İli’ne ait analizler}

Başkent EDAŞ kapsamında yer alan Karabük İlinde 4 yıl (2015 - 2018 yılları arası) içerisinde yeni yapılan 1814 adet yapının Elektrik İç Tesisat projesinde belirtilen kurulu gücü, ve aynı projede hesaplanan talep gücü ilgili dağıtım şirketi kaynaklarından elde edildi. [9] Ayrıca 1814 adet yapıdan enerji hizmeti alan 5591 adet müşterinin 4 yıllık gerçek tüketim değerleri yine ilgili dağıtım şirketi kaynaklarından elde edilerek hesaplanan talep gücü ile tüketim anında ki gerçek demant değerleri karşılaştırılarak analiz edilmiştir. [9] Şekil 1'den talep gücü; mevcut katsayılar kullanılarak hesaplandığında kurulu gücün \%50 si seviyelerine inmekte olmasına rağmen demant gücü ile arasındaki mesafe göz ardı edilmeyecek kadar büyük olduğu görülmektedir.

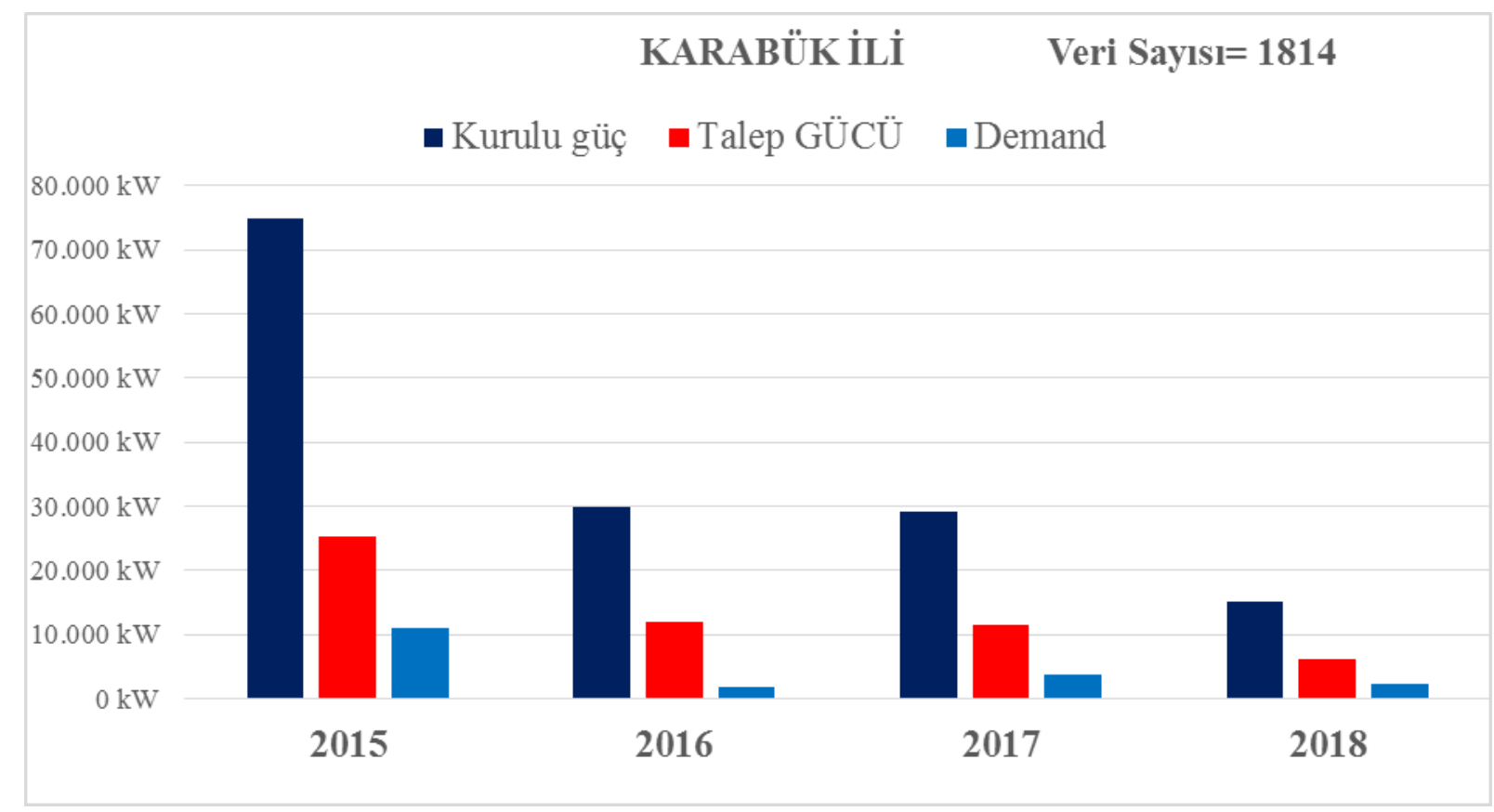

Şekil 1. Karabük ili kurulu, talep ve demand güç verileri

Şekil 1'deki verilerin tam olarak anlaşılabilmesi için Şekil 2'de talep ve demand güçleri verilmiştir. 


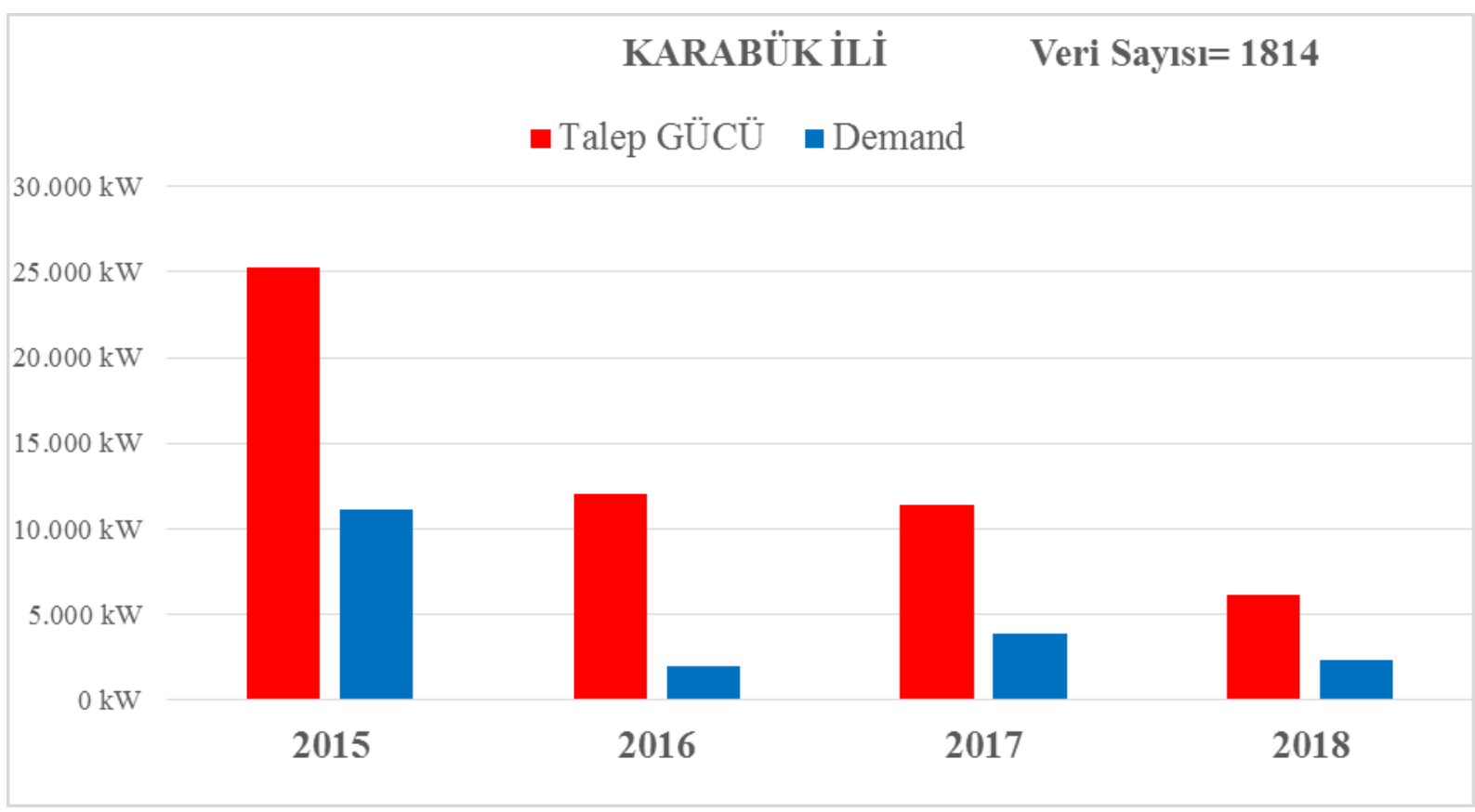

Şekil 2. Karabük ili kurulu, talep ve demand güç verileri

Şekil 1'deki güç değerlerin sayısal değerleri Tablo 1'de verilmiştir.

Tablo 1. Karabük ili kurulu, talep ve Ddemand güç verileri

\begin{tabular}{|c|c|c|c|}
\hline \multicolumn{2}{|c|}{ KARABÜK ILII } & \multicolumn{2}{|c|}{ Veri Sayısı= 1814} \\
\hline Yıllar & Kurulu güç & Talep Gücü & Demand \\
\hline 2015 & 74.759 & 25.245 & 11.099 \\
\hline 2016 & 29.868 & 11.989 & 1.954 \\
\hline 2017 & 29.134 & 11.439 & 3.847 \\
\hline 2018 & 15.077 & 6.182 & 2.315 \\
\hline
\end{tabular}

\section{Sonuç}

Gerçekleştirilen bu çalışmada Karabük ilinin (2015-2018) 4 yıllık gerçek tüketim analizleri incelenmiştir. Bu çalışma sonucunda demant gücü ile hesaplanan talep gücü arasında 1/3 oranında bir farklılık olduğu net bir şekilde görünmektedir. Bu da eş zamanlılık katsayısının incelenmesi gerektiğini ortaya çıkarmaktadır. Bundan sonraki çalışmalarda optimizasyon çalışmaları ile eş zamanlılık katsayı değerleri incelenebilir. Ayrıca talep gücü ile demand güç arasındaki fark değerlendirilerek maliyet analizleri de gerçekleştirilebilir.

\section{Kaynaklar}

Bin, Y., Kun, S., Dezhi, L., Xin, Y., Bin, L., \& Yiyun, L. (2018). Research on Power Flexible Load Regulation Technology Based on Demand Response. Paper presented at the 2018 8th International Conference on Electronics Information and Emergency Communication (ICEIEC).

Elrayyah, A. (2015). Droop based demand response for power systems management. Paper presented at the 2015 First Workshop on Smart Grid and Renewable Energy (SGRE).

Hong-Tao, C., Jian-Xue, C., Yang, D., Meng, Y., \& Ge, P. (2018). Local Consumption Model of Wind and Photovoltaic Power Based on Demand Side Response. Paper presented at the 2018 China International Conference on Electricity Distribution (CICED).

Imanaka, M., Baba, J., Shimabuku, M., Tobaru, C., \& Uezu, Y. (2015). A simple control method of waterworks pump power consumption for demand response. Paper presented at the 2015 IEEE Power \& Energy Society Innovative Smart Grid Technologies Conference (ISGT).

Jiarui, H., Dong, X., Jing, X., Chen, L., Ke, X., Rongjing, C., \& Chenlei, C. (2018). Research on Demand Response Strategy of Electricity Market Based on Intelligent Power Consumption. Paper presented at the 2018 China International Conference on Electricity Distribution (CICED).

Khare, A., Bajpai, S., \& Choubey, M. (2012). Measurement/Evaluation of electrical power demand/losses in wide spread 11/. 4 KV distribution system of JNKVV Jabalpur; Maximum Demand controlled by DG set. Paper presented at the 2012 IEEE International Conference on Power Electronics, Drives and Energy Systems (PEDES). 
Quan, W., Baoguo, S., Xiandong, T., Yuanbing, Z., \& Zhaoguang, H. (2009). Meta-synthetic seminar hall for power supply and demand research. Paper presented at the 2009 IEEE International Conference on Systems, Man and Cybernetics.

Rewatkar, K., Kewte, S., Rewatkar, S., \& Pote, X. (2017). Industrial power load management using maximum demand meter. Paper presented at the 2017 International Conference on Energy, Communication, Data Analytics and Soft Computing (ICECDS).

Sun, H., Jiang, W., Wang, B., Guo, Q., Zhang, B., \& Wang, K. (2010). Preliminary research on power demand model of high energy consumers for smart grid in China. Paper presented at the IEEE PES General Meeting.

Wang, X., Chen, H., \& Jiang, X. (2016). Cost compensation mechanism for high wind power integration considering demand respond. Paper presented at the 2016 IEEE PES Asia-Pacific Power and Energy Engineering Conference (APPEEC).

Westermann, D., \& John, A. (2007). Demand matching wind power generation with wide-area measurement and demand-side management. IEEE TRANSACTIONS ON ENERGY CONVERSION EC, 22(1), 145.

Xie, L., Zheng, H., \& Zhang, L.-Z. (2007). Sensitivity analysis on long-term power demand by Grey System. Paper presented at the 2007 International Power Engineering Conference (IPEC 2007).

Zhao-guang, H., \& Xian-dong, T. (2006). Study on the architecture of national electric power supply and demand simulation system. Paper presented at the 2006 International Conference on Power System Technology.

Zheng, L., Wenbo, X., Kui, W., Dawei, Y., Jin, Z., Yuanyuan, L., . . . Lu, L. (2018). Research on power demand forecasting based on the relationship Between economic development and power demand. Paper presented at the 2018 China International Conference on Electricity Distribution (CICED).

[1] TMMOB ELEKTRIKK MÜHENDÍSLERI ODASI, Elektrik İç Tesisleri Yönetmeliği. ANKARA, 1954.

[2] A cellular automaton based model simulating HVAC fluid and heat transport in a building. Modeling approach and comparison with experimental results A.SaizaJ.F.UrchueguíabJ.Martos https://doi.org/10.1016/j.enbuild.2010.03.024

[3] Semi-automatic approach for thermographic inspection of electrical installations within buildings A.S.Nazmul HudaaSoibTaibaMohd ShawalJadinbDahamanIshaka https://doi.org/10.1016/j.enbuild.2012.09.014

[4] Energy performance building evaluation in Mediterranean countries: Comparison between software simulations and operating rating simulation Lamberto Tronchin *, Kristian Fabbri

DIENCA-CIARM, University of Bologna, Viale Risorgimento 2, I-40136 Bologna, Italy Received 17 July 2007; received in revised form 3 October 2007; accepted 9 October 2007

[5] Benchmarking Productivity Indicators for Electrical/Mechanical Projects Awad S. Hanna, M.ASCE; Pehr Peterson; and Min-Jae Lee, S.M.ASCE https://ascelibrary.org/doi/abs/10.1061/(ASCE)0733-9364(2002)128:4(331)

[6] Framework of Success Criteria for Design/Build Projects Albert P. C. Chan; David Scott; and Edmond W. M. Lam https://ascelibrary.org/doi/abs/10.1061/(ASCE)0742-597X(2002)18:3(120)

[7] Elektrik İç Tesisleri Proje Hazırlama Yönetmeliği http://www.resmigazete.gov.tr/eskiler/2003/12/20031203.htm

[8] Kablo Bacasi Ve Enerji Odasinin Ölçü Ve Detaylari İle Uygulama Alanlarina İlişkin Esaslar http://www.emo.org.tr/genel/bizden_detay.php?kod=59703\&tipi=2\&sube $=16$

[9] Başkent EDAŞ 